\title{
Contested conservation - neglected corporeality: the case of the Namib wild horses
}

\author{
Robert Pütz and Antje Schlottmann \\ Department of Human Geography, Goethe University Frankfurt, Frankfurt am Main, Germany \\ Correspondence: Antje Schlottmann (schlottmann@geo.uni-frankfurt.de)
}

Received: 18 February 2019 - Revised: 24 March 2020 - Accepted: 26 March 2020 - Published: 19 May 2020

\begin{abstract}
This paper is concerned with a herd of wild horses that struggles to survive in the Namib Desert. This case, we argue, reveals ambivalences and critical paradoxes that go along with putting nature-culture dualisms into conservation practice. At the same time, we argue that there are aspects of bio-power involved which cannot be understood properly without taking into account the sphere of the body. We hence analyse in detail the "struggles over nature" that enfold around the questions of whether and with what means humans should intervene in the predicted extinction of the horses. Thereupon, we elucidate the relationships between sustainable conservation work and the symbolic as well as material practices of territorialization. Our investigation then puts focus on the fact that the conflictual border work appears also as an incorporated practice of subjects. Thus, while elaborating on a phenomenological approach, we explore the field of a contested conservation by employing the concept of intercorporeality. Such a "more-than-discursive" approach to human-animal relations, we finally argue, helps to reposition research for conservation as well as conservation practice towards learning about, and with, the lived bodies of all actors involved.
\end{abstract}

\section{Prelude}

When we arrive at the designated spot, we can see the horses. Some stand in the distance, and others start to move towards us and the cars. We wait, enveloped in a cloud of sand and dust stirred up from the dirt road, until the biologist arrives in the third car with the trailer. Now the horses come closer. They look friendly, curiously sniffing and nuzzling us but also nudging each other in a peaceful way. Their shape fits our expectations based on what we have read in the local newspaper and what we have seen in hundreds of images from the internet: slender, weak, hungry. Or is it because we expected them to look like this that they do? It is hard to separate our preconceived notions from the actual horses we now encounter. While we stand and ponder, the biologist starts to offload the hay bales from the trailer using a big pitchfork. The feeding begins. She works efficiently in contrast to us, who, with laboured effort, try to lend a hand. Along the way, she manages to answer the myriad of questions we ask. However, though she talks a lot about the Namibian wild horse, she seems to avoid talking to the animals under her care. Her words are reflexive, her language carefully selected. Her movements and glances are affectionate. Her attitude ambiguously mirrors both joy and restraint. After a while, the horses gradually begin to scatter. We leave them. Bundles of hay tumble gently through a landscape that looks in many ways completely hostile to life.

\section{Introduction and positioning}

Our story is located in the Namib-Naukluft National Park in south-western Namibia. For the past 100 years, a herd of 150 to 300 wild horses has lived here. Ever since their settlement, these horses have been in danger of extinction due to recurrent droughts. In recent years, moreover, wildlife managers observed a successive encroachment of hyenas that slay foals and mares so that not a single foal survived in the years 2017 and 2018, and thus the herd decreased significantly. While some people, such as the national park manager from the Ministry of Environment and Tourism (MET) or private game farmer, among others, claim this trajectory to be "nature's course", other actors from local NGOs and the 
tourism industry call for (and engage in) the horses' rescue and conservation.

In what follows, we aim to analyse in detail the "struggles over nature" that enfold around the questions of whether and with what means humans should intervene in the predicted extinction of the Namib wild horses. The relational term conservation thereby reveals itself at all points to be contested, be it as a concept on a discursive level, as a political field of human and non-human practice or, not the least, as an embodied norm within an individual. The idea of "contested conservation" helps us to observe its normative or taken-forgranted use and to enlighten the multitude of power-related conflicts it comprises, three of which we focus on in this paper.

First, there are conflicts on a discursive level. We will shed light on negotiations about for what and whom exactly "sustainability" shall be reached, which aspects of nature are deemed worthy of protection, and how animals come to represent the Namib's local ecosystem. Such discourses also imply the question of whether the wild horses - be it naturally or legally - belong to this particular ecosystem or not.

Secondly, we will elucidate the relationships between conservation work and the symbolic as well as material practices of bordering. Territorialization in nature conservation often serves a dualistic concept in which nature is a counterpart to cultural ordering of any kind. However, dualistic practices of bordering prove particularly conflictual when considering how horses and their habitats in practice resist rigid borders. We elaborate on this approach to the political ecologies of the horses by employing perspectives of assemblage and hybridity.

Thirdly, our analysis will reveal that conflictual border work appears also as an incorporated practice of subjects, whose embodied norms of, for instance, sustainability or "wildlife", lead to emotional conflicts while working with horses. This holds particularly true in situations where human actors need to make decisions concerning the life and death of individual horses under their care. In this final step of our inquiry, we thus explore the struggles in the field of nature conservation by employing the concept of intercorporeality. While discarding a general human-non-human divide and anthropocentric concepts of the body we aim to make visible reciprocal, sometimes contradictory, bodily involvements.

The concluding section discusses the potential of our "more-than-discursive" approach to human-animal relations based on our findings ${ }^{1}$.

\footnotetext{
${ }^{1}$ Our findings draw from qualitative fieldwork and a multimethod analysis of its results. It comprises interviews with officials of the Ministry of Environment and Tourism (MET), in particular with a national park manager; on-site interviews with wildlife activists from NGOs such as the Namib Wild Horse Foundation (NWHF), in particular with a wildlife biologist; and in-depth interviews with tourism entrepreneurs, in particular with managers
}

We locate our work in the emerging and gradually evolving fields of environmental humanities and animal geographies. However, by drawing on various theoretical strands and negotiating respective perspectives, our inquiry framework evolves throughout the paper. Due to our background in the tradition of poststructuralist human geography, our first view employs text-centred approaches and recognizes nature as a social construction (Demeritt, 2002), performed in terms of speech acts (Searle, 1995) or discourses in the Foucauldian tradition (Foucault, 1970). Though we do not propose an ontological divide of nature and culture, we highlight the importance of continuous practices of dividing, categorizing and separating as both semiotic and material practices. Understanding these practices, we assert, however, cannot go without taking into account the spatial dimension of human-nature relations in general and the territorial dimension of human-animal relations in particular, as Whatmore (2002) or Urbanik (2012) pointed out comprehensively. In the last part of our exploration, however, we argue that even assemblage or hybridity approaches are not sufficient in grasping the inter-agencies between bodies and environments. This puts us close to post-anthropocentric approaches (Lorimer, 2015; Rutherford, 2011) and to concepts of encounter (Barua, 2016, 2017), to recent theoretic impulses from material ecocriticism (Iovino and Oppermann, 2014; Alaimo, 2010) or post-dualist eco-feminism (Gaard, 2011; Alaimo, 2016; Vakoch and Mickey, 2018), and, finally, to well-known strands of phenomenology that stress the significance of intercorporeality (Husserl, [1913] 2009; MerleauPonty, [1945] 1962; Plessner, [1941] 1970). However, we do not understand our theoretical elaboration as teleology. Rather, while stressing uncertainty as the central momentum of post-human approaches (De Lauretis, 2004:368), we aim to critically bring out concurrent and continuous processes of materiality and discursivity, of bodies and narrations, without necessarily proposing a common epistemology. As a consequence, the paper methodologically oscillates between - and at the same time combines - semantic, discursive and nonrepresentational approaches.

\section{The wild horses of the Namib}

\subsection{Origins}

The ancestry of Namibian wild horses was key to Namibian (colonial) history. Without them, the history of min-

of a private game farm that specialized in horses. However, for reasons of protection of data privacy and due to ongoing delicate negotiations, we decided not to present information about our interlocutors in more detail. We analysed programmatic strategies (official strategies for national park management and others) as well as public print media (articles and letters to the editor in the Namibian press coverage) and web forums in social media (Facebook). Interviews were conducted in both German and English and were occasionally translated into English. 


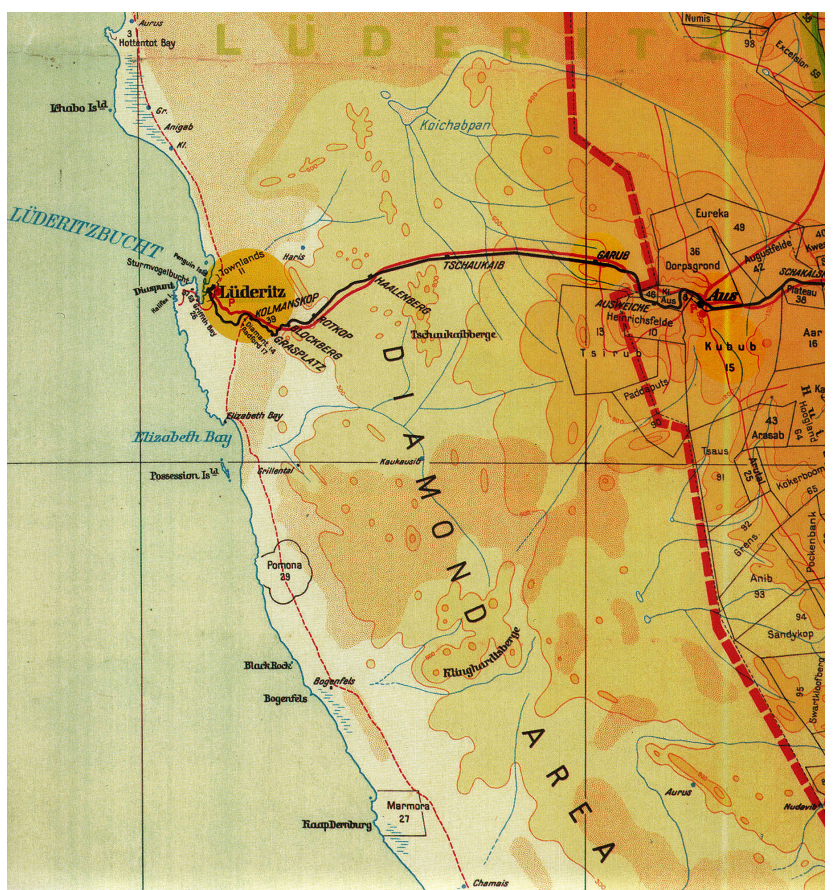

Figure 1. Historic map (year unknown, probably around 1910) of the southern part of the Namib. In this region, in particular in the "diamond area", the horses were introduced by German colonialists as workforce for transport and military. Today, the wild horses live around Garub. The border of the Namib-Naukluft Park crosses their habitat in the south (along the historic railway) and in the east (east of Garub; Goldbeck et al., 2011:26).

ing and extraction, of exploitation and suppression as well as war, would have been different. Until today, their symbolic meaning in the context of national identity has thus highly been contested. Sources agree that they are descendants from a European horse breed and that they settled at the end of the 19th century in the region around Garub, which lies $100 \mathrm{~km}$ from Lüderitz at the south-western edge of the Namib Desert (Goldbeck et al., 2011; Fig. 1). The population has different lines of ancestry. Originally, many horses were imported primarily for their labour value (Fig. 2) as well as for breeding or horse racing to the colony of DeutschSüdwestafrika (1884-1915). A second line of ancestry can be traced to horses needed by the German "Schutztruppe" in the build-up to World War I (Fig. 3). Historical documents report shiploads of more than 4000 horses during that time period. When German troops fought against the South African Union, their horses mingled with the so-called "Kap horses", a new breed. This is the third line of ancestors of today's "Namibs".

An air strike near the settlement of Aus dispersed thousands of stationed cavalry horses during the war. They mixed with the breeding horses from a deserted stud farm south of Aus. Gathered in larger herds and driven by the search for water, they finally found a well close to Garub. This well, ac-

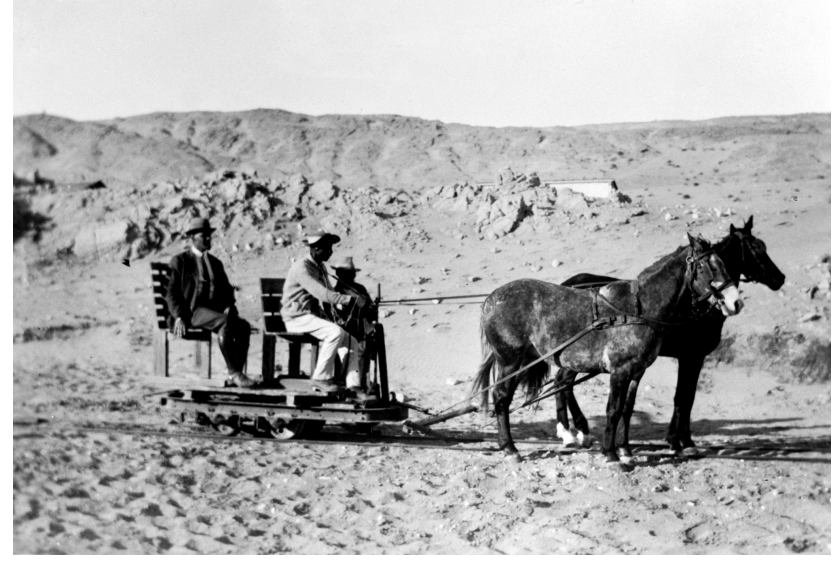

Figure 2. Working horses on the diamond fields (photograph: Bildarchiv der Deutschen Kolonialgesellschaft, Universitätsbibliothek Frankfurt am Main, 68-2178b-20).

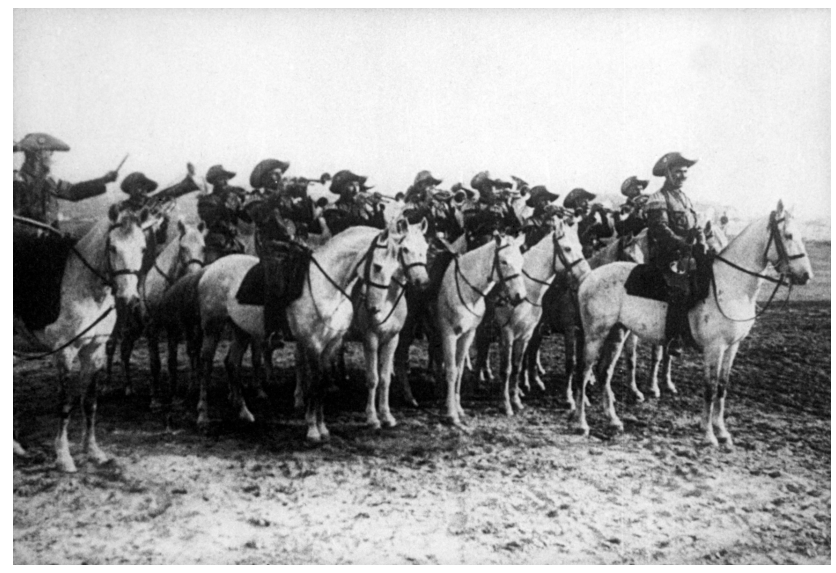

Figure 3. Mounted unit of the German "Schutztruppe" (Photograph: Bildarchiv der Deutschen Kolonialgesellschaft, Universitätsbibliothek Frankfurt am Main, 37-0600-39).

tively maintained to supply the troops and later the railway company with water, is one of the reasons why the horses could survive until present in this otherwise hostile, arid environment. Today, the national park management keeps the well open - solely for supplying water to the horses.

A second reason for the survival of the herd is the longtime limitation of (human?) access to their territory (Goldbeck et al., 2011:45). Until the 1970s, access was strictly prohibited in order to protect the local diamond resources. In 1986, the former forbidden zone became part of the Namib-Naukluft Park. In the course of this administrative change, the horses suddenly became a national subject of conservation. Moreover, their territory was completely fenced off due to a high risk of poaching. However, though the fencing protected the horses from human interference, it also restricted their mobility and their potential pasture. 


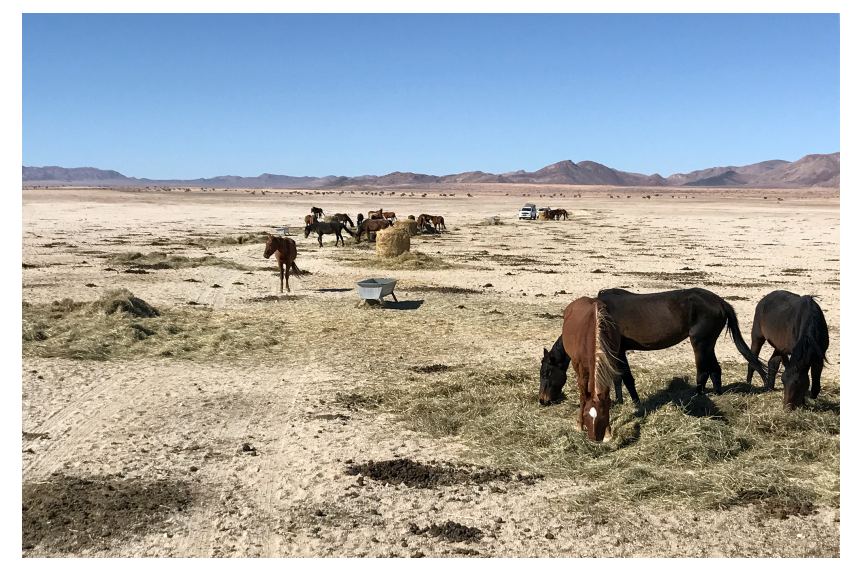

Figure 4. Feeding of the horses with hay (2017, near Garub; photograph: Robert Pütz).

Finally, the Namib horses of today survive because they are supplied with extra food in times of drought. Only as recently as the 1990s did people link the recurring droughts within the past 100 years to the death of many horses. The growing interest in environmental tourism made the situation visible to the public, on both a national and an international level. When a heavy drought towards the end of the 1990s resulted in visions of haggard and dying horses, public exclamations and emerging private initiatives, in particular the Namibia Wild Horses Foundation (NWHF), put pressure on the Ministry of Environment and Tourism. As a result, it became legal to feed the horses with hay in times of drought (Fig. 4).

\subsection{Current conflicts}

From 2010 onwards, the system of protection by territorial isolation, frequent water supply and nutritional supplements began to face challenges. While in the beginning phases, due to favourable weather conditions and rich food supply, not only did the horses thrive but also springboks and oryx expanded into the area. However, a heavy drought beginning in 2014 put immense pressure on the ecosystem. While the antelopes and gazelles left the region, the horses could not because they strongly depended on the waterhole in Garub. Moreover, the fences of the national park prevented them from moving to more humid private farmland at a higher altitude. Originally erected to protect the animals, the fences now turned into a trap for the horses. The then weakened horse population attracted hyenas to settle in the area, attacking horses instead of following antelopes. While the hyenas did not have any problem crossing the fence, their prey could not get out.

As a result, in 2017 there were only around 110 wild horses in Garub remaining, of which two-thirds were stallions (in 2020 the numbers changed to 79 total and 46 stallions; see Swilling, 2020). This alarming gender ratio and the decreasing overall population led the NWHF to publicly announce the total extinction of the horses within the coming 6 months. The MET reacted to the growing pressure from the media. However, because hyenas are also subject to environmental protection regulations, it was not deemed permissible to shoot them but instead to feed hyenas with meat from private game farms. Today, after a short respite in horse population mortality (as four new foals were born in the summer of 2018), the stock has again decreased rapidly, and the hyenas killed all foals by the end of 2018. In an open letter to the MET, the NWHF called for immediate action to rescue the horses and to weaken its non-interference policy regarding the wildlife in the national park (NWHF 19 November 2018).

\section{Whose conservation? What nature?}

The story so far reveals how conservation practice is deeply entangled with diverging ideas of nature and wildlife. There are various imaginations, norms, values and goals at play. They often hide behind allegedly consensual, yet highly underdetermined terms or, in Laclau's words "empty signifiers" (Laclau, 2002). Sustainability, for instance, promises to reconcile contradictory social practices such as the exploitation and conservation of nature (Tremmel, 2003:63; Schwartz, 2015). Instead of employing such semiotics uncritically, we thus are suspicious of different actors using particular terms for their diverging strategies in a field of unbalanced power resources and sovereignties of interpretation (Schlottmann et al., 2010). From a social constructivist or moderate actornetwork perspectives (Demeritt, 2002; Thrift, 2003), imaginations of present and future natures are crucial. Ideas of wildlife, plants and animals, in particular, often correlate with a sense of territoriality. Free-roaming animals, for instance, are indispensable for the social construction of an untouched landscape and the rural idyll (Macnaghten and Urry, 1998; Jones, 2003). For representations of Namibian wildlife, the big five (elephant, rhino, cheetah, lion and buffalo) are iconic as flagship species. Using the example of conflicts around the open grazing land of mustangs in the US, Pütz (2017) shows that even horses can be significant elements in the construction of wildlife. Related discursive quarrels unfold around the question of whether these horses are "really" wild horses or "only" feral horses, whether they are an indigenous part of the local natural environment or its opponent, and hence whether they are worth protection or invaders in the local ecosystem and a threat to farmers' livelihoods. The debate surrounding the Namib horses echoes this discourse ${ }^{2}$. According to the Constitution of Namibia, Article 95, and official conservation guidelines, wildlife is subject to particular protection (MET, 2013). However, whether

\footnotetext{
${ }^{2}$ Similar struggles about the ecological status of the horses ("native" or "pest") can be observed in other national discourses as well. In Australia, for instance, the status of the "brumby" horse as a part of nation-building narratives is politically highly contested.
} 
the horses as species "belong" to the Namibian indigenous wildlife is not clear. It remains an open question which species and individual animals survive the battle for the highest symbolic relevance and thus become representative of Namibia's natural landscape. We here identify rivalling schemes of nature conservation in how they handle wild or feral horses, two of which - the most influential - we sketch out in more detail below ${ }^{3}$. En route, we introduce some of the main human protagonists in the field: first, a park manager who represents the Ministry of Environment and Tourism and works on the horse issue for many years; second, tourism entrepreneurs who build their businesses upon the horses, both materially with regards to touristic encounter, and symbolically by shaping "horse-like" atmospheres on their farm; and third, a wildlife biologist, who devoted her life to the study and, as a consequence, the conservation of the horses.

We refer to a first position, according to Mace's (2014) framework of the history of changing views of nature and conservation, as "nature for itself". It subscribes to an imagination of a pristine nature, absent of human influence. According to this view, wildlife territories, including both plants and animals, should be left alone in order to sustainably preserve their intactness and an untouched nature.

As a MET representative puts it,

I think sometimes people make the mistake of getting involved emotionally. ... I know the hyenas hunt, they are not only scavengers. But ... you may not get involved with the drought. You cannot change it. It is Act of God. The survival of the fittest. (national park manager, 2017)

Along with this position follows the notion that horses introduced and kept alive by humans cannot be genuinely considered wild horses. Moreover, this view asserts that their conservation endangers ecological sustainability of "real" or indigenous nature and thereby neglects ecosystems as emergent ecologies (Parreñas, 2018). Most notably, this position systematically ignores the argument that a managed nature is always socially constructed. The underlying conceptualization of a pristine nature is rather essentialist, and often nature becomes a synonym for divinity. This concept of "nature for itself" thus also delineates which species belong to local na-

\footnotetext{
${ }^{3}$ Genetic analyses show the isolation and low genetic variation of the Namibs for more than 100 years, providing reason for claiming them to be "wild" (Cothran et al., 2001). Yet in the sense that they clearly do have domestic ancestors, they must be labelled as "feral". Either way, we here stress the point that either categorization is socially constructed and first gathers meaning in language use and discursive performance. The tourist entrepreneurs, for instance, refer to the attribute "wild" because its semantic space is most relevant for transporting an adventurous tourist imagination. The park manager, in contrast, employs a realist approach that helps with deciding on adequate management instruments. On a metalevel of observation, the common ground of the constructions would be the term "free-roaming horses".
}

ture by determining who was first and hence has the stronger claim to stay (and to survive):

And the MET also said, which we understand, that they are a native species and the horses are not. So, if one has to stay and one has to go, the hyenas should stay and the horses should go. Because the hyenas belong there, it was always their territory, even if they haven't been there in big numbers and even if they haven't been so 'resident' as we call it. (tourism entrepreneur, 2017)

An opposite position, in Mace's (2014) framework, called "nature for people", understands wild horses as a species that is characteristic for the region and an important part of the local ecosystem. This fact, protagonists argue, requires immediate action for wild horse protection. From this perspective, sustainability can (today) only be achieved by human intervention that recuperates ecological balance. Thus, if the hyenas turn out to be a problem for the horses' survival, action needs to be taken:

Since the situation developed as it did over the last ten years, of the hyenas increasing there and coming here, and now they have established quite a nice little setup here at Garub. This situation is not sustainable with the horses. So they've killed all the foals for the last five years. (wildlife biologist, 2017)

The underlying concept of nature is a nostalgic and arcadian one: an imagination of a (lost) world in which human and animal coexist peacefully. The human, however, is the shepherd and responsible for the conservation of nature and for the survival of particular species (e.g. horses). Such a viewpoint often conceals underlying interests, i.e. economic, as it argues human interference "in the name of nature". The tourism entrepreneur, for instance, suggested moving the horses onto private farmland in order to "rescue them" from the hyenas, who may be shot on private land:

And we think it would be good if it's as close as possible to the area where they are now because that is kind of the same environment and habitat and it still remains as a tourism attraction in the area. Because it is really important for all of us. If you were to remove the horses completely, for Aus tourism it would really be a big, big blow. (tourism entrepreneur, 2017)

From this position, not only species but also their (sustainable) exploitation becomes a subject of negotiation. It is not a simple matter of biodiversity or conservation of species for themselves. Hence, the genetic survival of the horses is not only understood as a sustainable solution but also as central to the survival of the local tourism economy.

For the horses concerned, however, the question of which concept of nature prevails and whether they are labelled as 
pristine wild horses or feral invaders becomes a question of life and death. From one perspective, horses do not count as a "genuine" component of the wildlife park and hence probably must die therein. In the second view presented, they appear to deserve protection, whether for a sustainable ecosystem or a sustainable economy. Consequently, in the latter case, either the feeding programme of both horses and hyenas must continue or the hyenas must die. Since killing the hyenas in the park is illegal, the Namibian Wild Horses Foundation proposed shifting the horses onto private farmland. Thereby, the foundation forms an alliance with local tourism entrepreneurs. Such action, however, will continually engender questions such as whether protected or even privatized wildlife is still considered wildlife, whether one particular part of wildlife (e.g. the horses) is more valuable than another (e.g. the hyenas), and, not the least, whether sustainability of ecosystems is desirable for the ecosystems or rather for people and their economy.

\section{Conservation as territorialization}

While both positions seem at first glance to be opposing, they overlap concerning a fundamental nature-culture dualism (Steiner, 2014). This separation of nature and culture goes hand in hand with the practice of territorialization, as it occurs in conservation practice (Peluso and Lund, 2011). The dualism materializes territorially, which is in particular observable in the fencing of the park. The erected fence is intended to protect nature against human intervention, invasive species and other threats. At the same time, the enclosure helps put into place (and discipline) a lively and resistant nature to make it "manageable". Such territorialization, in its literal spatial sense, thus serves the overall aim of a temporal fixation that seems necessary for sustainability, understood as the conservation of a particular (ecological) condition. Fencing therefore has become a preferred means of biosecurity and nature conservation, despite of all the transactions and transformations that are taking place in biosphere (Hinchliffe et al., 2013). It follows viewpoints that understand nature and culture as distinct and serves to keep out those deemed foreign or invasive. It hence separates "pristine wildlife" from invaders, be it poachers, diseases or invasive species (Brockington, 2002). At the same time, fences regulate entry and the contact of humans such as tourists with the non-human wildlife within the park (Evans and Adams, 2016:216). To sum up, borders, be they material, administrative, juridical or semantic, have both a restrictive and an enabling side. They enable a fixation of the social relations of nature; in particular, they define belonging and property rights. They even define not only if (and where) an animal has a right to be protected but also to whom particular animals belong and who owns the right to exploit them (for tourism, for instance) or to kill them. On the other hand, borderlines restrict the mobility of both humans and animals, and while they define the spaces animals experience and live within, they are a fundamental part of the biopolitical ecology of wildlife conservation (Bluwstein, 2018).

In our case, practices of territorialization are highly contested as much as related ideas of sustainability. The rationale of the MET, for instance, focusses primarily on the borders of the national park. According to the MET, the wild horses do not belong to the pristine local nature of the park, though they live inside its borders. Thus, at the same time, the horses both do not deserve protection and do deserve it. Hence, paradoxically, though the MET does not have the horses on the list for conservation, it cannot agree to their relocation onto private farmland, as suggested by the NWHF:

They are part of our park. I cannot simply take them out and shift them onto a farm. (national park manager, 2017)

In contrast, the aim of the wildlife biologist is sustainable conservation of the horses' "natural living conditions" and their survival as a species. Her demand for territorial integrity fundamentally recognizes the horses and their spatial practice. She therefore generally objects to any borders that compromise the horses' mobility, and she combines arguments of social sustainability (horses as cultural and colonial heritage) with those of biological sustainability (conservation of local biodiversity in accordance with her view that the wild horses genetically became a "race of its own"4). Territoriality in the sense of the whereabouts of living and dying becomes crucial in this respect:

And the thing is also, it is not so easy to just take the horses [far] away. Because then, first of all you lose the heritage. And you lose the genetic peculiarities. Plus, they also don't do so well in other areas. ... Then they [might] rather be hyena food then - that's better for them. (wildlife biologist, 2017)

Against this background, we can see the border of the national park as a border of biopower in a Foucauldian sense (see Chrulew and Wadiwel, 2017). The border becomes relevant even for the hyenas, which may be shot on private farmland but not within the territory of the national park. The ambivalence of the fence around the Namib-Naukluft conservation area reflects the ambivalence of nature as both something worth protecting and a threatening force. Thus, regarding local native ecosystems and their biodiversity, the question remains whether the horses count as inhabitants or invaders. They are in virtual limbo. However, for the horses, hyenas inside the protected zone pose a severe threat, and the fence

\footnotetext{
${ }^{4}$ The MET, in contrast, argues that the horses were never really isolated from domestic horses, since local farmers eventually used them for their purposes and in turn marooned their sick or otherwise useless horses in the area. Consequently, for the MET there is no genetically distinct Namib wild horse existent.
} 
prevents them from fleeing into the secure outside. While for environmental managers the fence helps in locating, fixing and "sustainably" conserving a particular nature, it impedes the horses' spatial mobility. In this respect, the fence hinders the conservation of the horse species that various actors of civil society have so vocally advocated for.

\section{Crossing ontological borders}

Our case reveals the complexity of problems that accompany efforts to spatially institutionalize nature-culture boundaries. Geopolitics of sustainability, we here illustrate, continually reproduce this dualism and thereby create inconsistencies. Discourse analysis helps elucidate the conflicts in nature conservation that accompany diverging imaginations of nature, and they reveal how dualistic thinking is hegemonic. At the same time, one could argue that an analysis that focuses on discourses only comes up short insofar as aspects of materiality and agency of nature get lost in what Wolch (2002:730) has called the "writing out" of nature. By drawing on non-representational, post-humanist or network-oriented approaches (Whatmore, 2002; Haraway, 2003), Lorimer (2015:5) therefore proposes a "new ontology", which shall help to guide practices of conservation by disconnecting them from the idea of a biologically defined non-human nature worth protecting. Instead, he suggests a "multinatural ontology of wildlife" as a fundamentally nondualistic concept (Lorimer, 2015:32). This concept accepts the world as hybrid, as constituted in assemblages and as multiple in character in regards to spatio-temporal dynamics. In a sense of Deleuze and Guattari (1987), we see assemblages here as constellations of material and immaterial, corporeal, and incorporeal human and non-human elements.

In what follows, we employ these concepts for our case and consider their utility for a better comprehension of what is occurring with Namib wild horse conservation. In a second part, however, we suggest that these perspectives can be strengthened by post-human approaches following a new materialism and, as we emphasize here, even by much "older" phenomenological approaches that shed light on the corporeal dimension of human-wildlife relations and conflicts.

\subsection{Assemblage and hybridity}

Following Whatmore and Thorne (1998, 2000), wildlife is an assemblage of food, predators, humans, institutions, data, algorithms, discourses and materialities of different kind, in their words a "network of human-animal relations" (Whatmore and Thorne, 1998:436 pp.). From this perspective, the wild horses of the Namib as well as all related non-human entities in this interplay are attributed a degree of agency. They are able to resist human practices and to provoke agency of others. They interact with non-human organisms such as hyenas, other horses or hay; with human organisms such as the tourists they are fed by and who they occasionally might bite; and with caring conservationists or rangers. Their life and death constitute a network of NGOs, public authorities and other actors who are concerned with their case.

Moreover, the approach recognizes that the agency of the wild horses is embedded in contested discourses of conservation and respective interpretations of nature, wildlife or sustainability as well as powerful imaginations of wild horses in media representation. In the case of Namibia, the horses are also subject to postcolonial discourses, in which their colonial provenance is seen as a symbol either for freedom ${ }^{5}$ (even independence from the German colonists) or for guilt (for what the colonists have done) ${ }^{6}$. Here it becomes obvious how questions of the Namibs belonging to "native" ecosystems closely correspond with questions of how they feature in nation-building narratives as part of animal nationalisms (Gillespie and Narayanan, 2020).

Besides this cultural dimension of the conflict, calculative practices are a substantial part of the human-horse assemblage. The animals are counted, observed and controlled in their mobility. Algorithms of carrying capacity based on hydrological test series and tillering rates help managers make decisions concerning the animals' fate:

We calculate the carrying capacity for each park. We know we have rangers who go in and say 'large stock unit ... small stock unit'. (national park manager, 2017)

Material artefacts mediate the interactions of the wild horses with their surroundings. Besides fences, there are drinking troughs and feeding facilities, which affect the horses' spatial practices as well as their ability to be observed by tourists. These artefacts contribute to the economic value of the landscape through "mediation of nature-society relations" (Barua, 2017:284), resonant of Barua's "spectacular accumulation" (Barua, 2017:284; Fig. 5).

From an assemblage perspective, wild horses cannot be classified as belonging to a rigidly defined category of "nature". Assemblages are dynamic and continually changing. In theory, this assemblage concept antagonizes a naturecentred understanding of sustainability. The dualism of nature and culture presented in other theorizations does not serve any ontological differentiation in assemblage thinking. Yet empirically, by following how, when and why dualistic nature-culture thinking is employed, we can elucidate how certain (bio)politics are sustained (or challenged).

Many of our findings emphasize the suitability of the concept of assemblage and, in particular, that of hybridity, which sees animals as being constituted of biologically and so-

\footnotetext{
5“They have captured our imaginations and our hearts, and have come to represent fierce survival, the strong and rugged spirit of Namibia, and - freedom" (Gondwana collection, 2016).

6"There were one or two black-speaking Namibians, black people who thought like this: The horses were employed by German soldiers to kill my ancestors" (wildlife activist, 2017).
} 


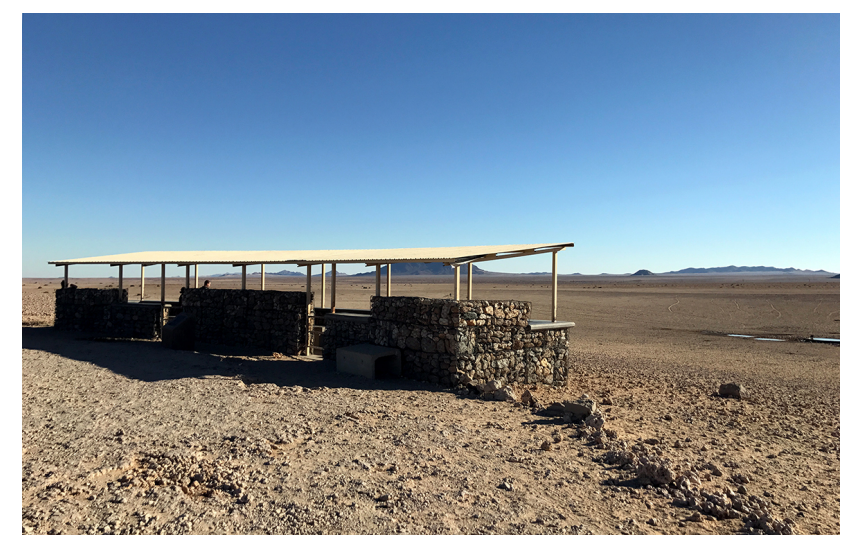

Figure 5. Observation point. Co-constitution of wildlife in the "natural-cultural contact zone" (Haraway ,2008): drinking troughs guide the horses towards tourist viewpoints and help designate how and where horses trod upon, and thus shape, the landscape (2017, Garub; photograph: Robert Pütz).

cially formed relations. The horses themselves, if we accept their agency, elude clear-cut classification. In their relation to humans, a border between nature and culture is elusive, depending on the (human) interests at hand. At the same time, following Lorimer (2007), horses bear a specific aesthtetic, ecological and corporeal charisma in the form of "biopower". This charisma oscillates between what humans categorize as nature or culture because it involves the biopower that emerges through interactions between humans and non-humans. Moreover, perhaps more than any other species, horses symbolize the human longing for a fusion with nature, as expressed for thousands of years in the symbol of the centaur. Their deeply hybrid character, the horse thing (see quote below), as emerging from or as arising through hundreds of years of living with humans, resists classification, both in discursive and material practice:

Because they do separate. Very few people I think can see them as wild animals.... If an oryx stands there with a broken leg they would say: 'Oh the oryx, what a shame'. But they would actually, at the end of the day, drive past. If it's a horse, very often it's a bit different. It's the horse thing that comes in. (wildlife biologist, 2017)

While the hybrid character concerning the ambiguity of the horses' status as invaders or natives causes ecological uncertainties, the hybridity of human-animal of the horses leads to ontological inconsistencies in their relation to humans. Their "encounter value" (Haraway, 2008) derives significantly from people experiencing the horses in situations of corporeal communication (Pütz, 2020) and their performance as "wild". This includes that on-site encounters, and in particular their visuality, should match culturally fostered imaginations such as galloping dust-raising herds, or rearing stallions, even if they are meager. In this view, respective photographs made by tourists not only commodify and govern the object of nature (see Rutherford, 2011:121 pp.). They also make the affects evoked by visual encounter replicable. On the other hand, emotional ties that arise in situations of sensory perception and that have been mediated for centuries through films, books or artwork contradict the horses' classification as something natural, pristine, untamed or, in other words, non-human. For the tourists and thus for the animals' economization, however, horses must in fact be both wild and tamed:

There is a couple paradox between 'wanting them wild' - and they must run around and they must show. And beautiful scenery and so. And the stallions must kick and scream and all that. But on the other hand, the people find it really nice, when the horses come up and eat out of the hand. Same person! And ... who wouldn't really cry out loud when the horses look like they look now: skinny and scruffy. (wildlife biologist, 2017)

This paradox derives from an anthropocentric perspective regarding the economic value of nature in tourism. Moreover, it elucidates protagonists' inner debate around wanting to conserve something wild while acknowledging that through the very act of conservation, wildness vanishes (or at least diminishes).

\subsection{Intercorporeality: the feeding situation}

As we pointed out, discourse analysis helps us track the manifestations of a nature-culture dualism in the contested multilevel field of nature conservation. Assemblage perspectives are fruitful in order to account for the bodily or material dimensions of conservation practices. They accept hybridity and elucidate consequences of non-human agency. However, we argue that both strands fail to fully grasp the multiple body-related aspects of situated practices, resulting in a significant blind spot. It masks not only the fact that the corporeality of actors makes a difference, even on the discursive level, but also the fact that human actors adopt discourses and norms of concepts such as sustainability or biodiversity and thereby condition their bodily sentience, which in turn directs the way they treat (certain) animals. Furthermore, when human actors meet animals, they might be moved to care about their well-being, or become concerned about their starvation. In this sense, the human body in what has been labelled the "non-human turn" (Grusin, 2015) becomes apparent as an open system, with the material environment being an intrinsic yet decisive part of it. However, while sharing this idea of transcorporeality (Alaimo, 2010), we insist that besides material non-human actors the inner tensions resulting from contradictions of embodied norms, on the one hand, and affects arising through co-presence, on the other hand, must be thoroughly considered. These tensions derive from the embodied drive to maintain a nature-culture binary even as in- 
terspecies encounters of mutual embodiment simultaneously dissolve this boundary. The latter phenomena of interspecies embodiment, in Merleau-Ponty's words, are experiences of “intercorporeality" (Merleau-Ponty, [1945] 1962)7.

The actors involved in the conflict around wild horses agonize over the question of what is (still) natural and what is an unnatural interference. Moreover, they experience contradictions that accompany their challenging the natural-unnatural frontier. This becomes obvious in their verbal reflections on the act of feeding:

And now we have a situation where we maybe became a bit weak and allowed to feed even the hyenas. Bow we feed the hyenas and we feed the horses. And that's of course not an ideal condition. (NWHF activist, 2017)

Feeding in the natural-cultural "contact zone" (Haraway, 2008:4) is a moment of intense interaction between humans and horses and a mutual experience of corporality (Dutton, 2012). The wild horses know when and where the feeding will take place. They flock around the expected feeding location and eagerly devour the hay thrown off the truck. The feeding furthermore triggers intense interactions amongst the horses. They constantly nudge and shove one another while eating. At the same time, they interact with material artefacts such as the hay, the truck and the troughs (see Fig. 4: the vastness of the place stands in sharp contrast to the abundant, yet not depicted multitude of natural-cultural entanglements). This "dance of encounters" (Haraway, 2008:4) includes the wildlife biologist and us as participant researchers. It involves the way our bodies relate to the horses as much as it involves the expressions of hunger the horses show or the gentle body contact of the most communicative horses. It is a prime example of crossing borders, which is clearly reflected in the biologist's actions. Thus, following a "thinking through the body" (Whatmore, 2002:3) approach, we can see her feeding practice as an embodied boundary work, a continuous attempt to keep the non-human "natural order" stable despite the human act of feeding and to meet the norm of protecting the horses in their wildness as an essential part of the local ecosystem. However, there are situations in which the motif of the human as the shepherd of nature takes over:

If it breaks the leg I'm going to put it down. If the injuries are fatal. If there is no chance the horse is

\footnotetext{
${ }^{7}$ Intercorporeality "contains a perception-action loop between the self and the other. The self's perception of the other's action prompts the same action in the self or the same action possibility. Conversely, the self's action prompts the same action, or its possibility, in the other's body." (Tanaka, 2017:339). By drawing attention to the body's ability to simultaneously sense and be sensed, Merleau-Ponty transcends the object-subject divide and conceptualizes the body as being constituted by its corporeal relations and interaction with other animate bodies (Meyer et al., 2017:XVIIII). In his later work, Merleau-Ponty described a horizontal kinship between humans and other animals (Westling, 2013).
}

going to survive. ... I don't leave a horse with a [broken leg]. I'm sorry. ... That I think is cruel: To see an animal suffering and don't put it down. (wildlife biologist, 2017)

Otherwise, the biologist tries hard to reduce her interference to a minimum of "scientific" practices of measurement or observation in order to respect nature's boundaries:

When I started, it was to me: I'm not going to touch them. I'm not going to try to touch them. If they come to me I'm not going to chase them away. So I keep a line. So I don't make an effort to make friends with them. And I've always just kept that. So I - I mean, I love them as much as I love my domestic horses. But I understand life and death. (wildlife biologist, 2017)

Incorporated boundary work thus always means working with one's own emotions. As an activist of the NWHF puts it,

They still all have a name. Some just strike you a bit more. Yeah, obviously - there are certain individuals that I particularly like. And I really get crossed if the hyenas catch those ones. But, it's life. It's the circle of life. (wildlife activist, 2017)

In the case of the biologist, she attempts to dissociate from an emotional tie, which is well accepted in relation to a (in particular one's own) domestic horse but not in relation to wildlife. Rationally, she claims to restrict emotionally driven forms of interaction and works against her affective impulses that come with taking care of the horses. This undertaking results in an ongoing inner contestation along with a dynamic process of reconstructing and deconstructing the human-nature divide.

From a phenomenological perspective of intercorporeality, Merleau-Ponty addresses related situations of mutual embodiment in which our felt body is affected by expressions of the other and vice versa (Fig. 7). The expression of pain from an injured or suffering horse, for instance, affects the human (and evokes the human impulse to take care of another being) and translates into the corporeality of the wildlife biologist. She experiences and feels it in her very own body. This corporeality, in turn, influences her behaviour towards the horse and modifies in a permanent mutuality the corporal condition of both of them. Essentially, it creates an intercorporeality in which the human-nature dualism dissolves.

In addition to the concept of intercorporeality, we find the phenomenological differentiation between Körper and Leib insightful. According to Husserl ([1913] 2009) as well as Plessner ([1941] 1970; 1982), Leib denotes the lived body one "is" through experience ${ }^{8}$. In contrast, Körper means the

\footnotetext{
${ }^{8}$ Etymologically, Leib stems from Old German Lip, as well as the Old English life, denoting "animated corporeal existence; con-
} 


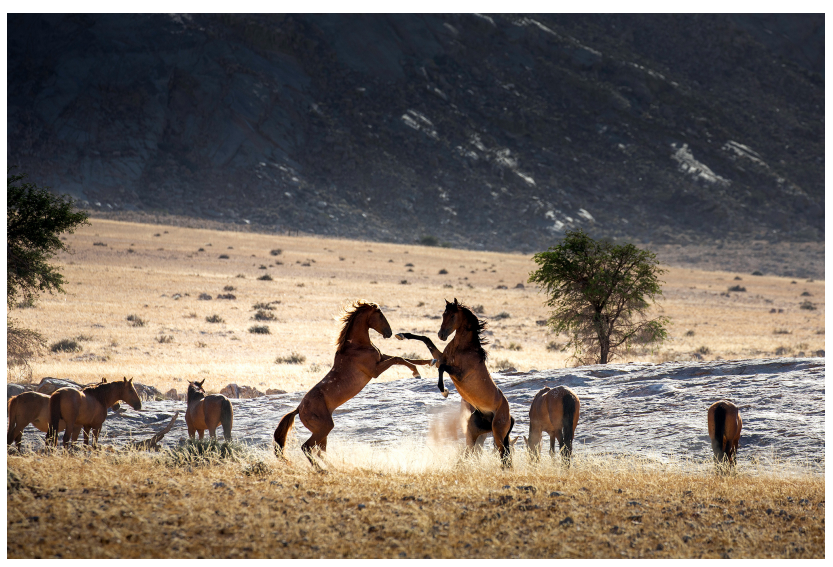

Figure 6. "Performing" stallions (2018, near Garub; photograph: Teagan Cunniffe).

material body, hence the physical body one "has"9. Körper encompasses the material body as well as the socially constructed image of one's material body. Leib is the body with which we experience the world and with which we express ourselves to the world. According to this distinction we can understand practices of the park management as Körper practices, be it efforts in population control, the territorial distribution of animals and their bodies, the establishment of norms of healthy animal bodies, or the assignment of a particular role in the local ecosystem. In the sphere of the Leib, in contrast, we find all aspects of emotion and affect of the humans and horses involved, such as fascination, curiosity, empathy or care.

Employing this theoretical framework, our examples elucidate the contradiction when tourists meet the wild horses, e.g. the noticeable tension between "wanting them wild" and the desire to feed them. The tourist expectation of and demand for "wild" behaviour and "wild" appearance of the horses arise from media and popular discourse of wildlife, and their assumed "typical behaviour" and appearance, in particular that of stallions. Such discourses form the horses' material body (Körper) into the body images that tourists expect to observe. Thus, through the very acts of horse spotting, the horses are then expected to behave and look accordingly (Fig. 6). On the other hand, the tourists' bodies are shaped by the visual encounter as well. In the way Alaimo (2010) puts forward, they are intrinsically tied to their environment in mutually constitutive actions. Moreover, these expectations along with physical objects create specific more-thanhuman contact zones (in the sense of the Haraway, 2008, multispecies understanding of the Pratt, 1991, contact per-

dition of being a living thing" (https://www.etymonline.com/, last access: 15 January 2020).

${ }^{9}$ Etymologically, Körper stems from Latin corpus, similar to "body" from Old English bodig: referring to the "physical structure of a human or animal; material frame, material existence of a human" (https://www.etymonline.com/, last access: 15 January 2020).

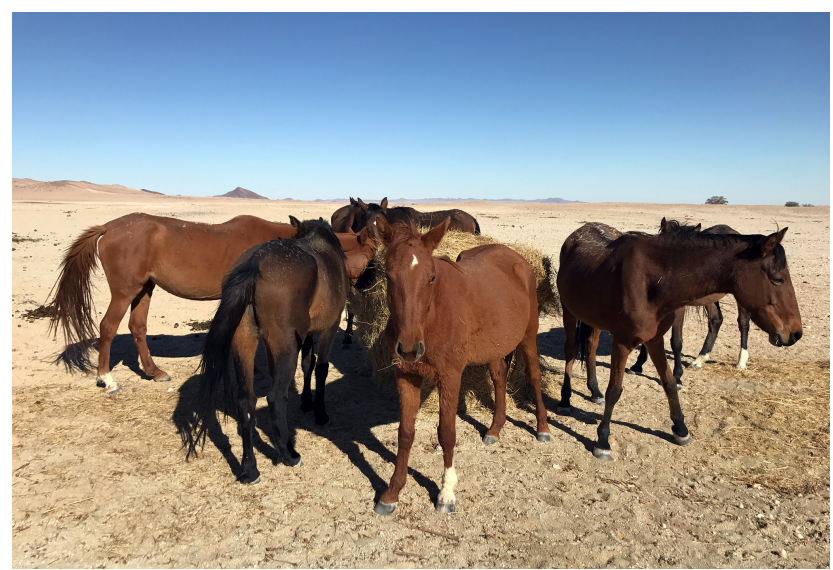

Figure 7. "I live in the facial expressions of the other, as I feel him living in mine." (Merleau-Ponty, 1964:146): a moment of intercorporeality in a feeding situation (2017, near Garub; photograph: Robert Pütz).

spective), which in our case are designed by park management practices. Intercorporeality of human-horse encounters is mediated through technologies of control (wells, feeding) and containment (fences), which enable encounter value for different actors, mainly tourists. In Garub, for example, drinking wells and a viewpoint guide horses and tourists into a kind of spectator arena (Fig. 5). As on many private wildlife farms, these "wild" animals in the national parks are bodily produced in order to meet discursively constructed and performed expectations while following visual grammars of pristine nature (Rutherford, 2011). This so-called "encounter value" of animal life has been astutely discussed by Barua (2016) in the case of elephants and lions in India. The expressed empathy upon encountering a suffering horse, in contrast, we understand as an experience of the lived body $($ Leib). Like the desire to feed the horses, it is fully comprehensible only in situations of immediate and close contact with the horses in the course of inter-corporeal experience. The reoccurring contradiction expressed in the quote of the wildlife biologist emanates from the tension of bodily experiences between the realms of Körper and Leib.

\section{Conclusions: neglected corporeality - and how to make it observable}

Based on our case study on the Namib wild horses, we argued that focusing on the body in a phenomenological way helps profoundly in better understanding human-animal or animal-human encounter. In particular, we find promising approaches, which conceptually distinguish the material and the lived body (Körper and Leib).

Latour (2004:205) posed that "to have a body is to learn to be affected, meaning 'effectuated', moved, put into motion by other entities, humans or non-humans". According 
to Lorimer (2015:7), nature conservation, or, in his words, "conservation after nature", should be a dynamic and preliminary undertaking that accepts and activates other forms of knowledge. Scientists should derive such knowledge from "learning to be affected" (Lorimer, 2015: 35):

Here, knowledge about the nonhuman world emerges out of situated, embodied, and technological encounters with the nonhumans that are the subject of research. The bodies of scientists are vital for this endeavor. It is only through training and experience that a scientist can learn to be affected by their target organism, ecology, or process.

However, as our case study illustrates, scientists in particular might bear inner contradictions of embodied norms and ethical values on the one hand and affective and emotional responses through situations of encounter on the other hand. When working with their "target objects", they are caught in inner contestations which make these objects an abstract wild species at certain points and then later an intimate horse with a name. In this respect, we agree with Bruckner et al. (2018:4), who criticize approaches whose "characterizations of affect simplify interactions with species, generalizing affective properties to an entire species". Employing tools that the affective turn brought to the methodological spectrum of qualitative research (for an overview, see Knudsen and Stage, 2015) therefore seems indispensable to investigate (and empathize) profoundly the corporeal and emotional imbroglios individuals are entangled in and driven by in practices of caretaking (see also Parreñas, 2018).

The differentiation of Leib and Körper, however, helps to shed light on involved inner contradictions and the ways they underlie conservation praxis. Moreover, it helps to capture the respective stresses at play in situations formed by the mutual agency of animals and humans. The notion of "affect", though powerful in highlighting non-verbal or non-rational essentials of praxis, might still suggest a one-way concept of someone or somewhat acting in relation to humans, hence influencing in terms of having an effect on "us". Instead, we suggest conceptualizing affect consequently as mutual. Such a concept then would be the condition for conceptualizing intercorporeality, which emphasizes the mutuality of bodily experiences as well as the experience of bodily mutuality. Instead of evoking the idea of animals or nature affecting humans with the consequence that scientists should "learn to be affected" (Lorimer, 2015:35), the concept of intercorporeality stresses the mutuality of affect in human horse encounters. A close examination of intensive, lived human-animal relations of intercorporeality could then reveal, at least temporarily, the dissolution of dualisms, with nature-culture being one of many substantial dualisms we live by. Learning to be intercorporeal in this respect could shed light on relations of guide dogs and their blind human counterparts in the mutual act of seeing or those of horses and riders in their mutual embodiments in the act of riding (Maurstad et al., 2013; Pütz, 2019).

Beyond the given examples, the concept of intercorporeality - enriched with the differentiation of Körper and Leib helps to explicate the formation of identity in human-animal encounter. Understood as perpetual performance of identification of and with the environment, identity must be considered as fluid, dynamic and situational. While following socio-psychological concepts, "identification of" (someone or something) can be related to living bodies (horses as endangered species, the Namib as wildlife territory with a certain carrying capacity, etc.), and "identification with" (someone or something) can be related to the lived body. However, from a phenomenological perspective, we can refine this matrix further with a third form of identity, which might arise in situations of experiencing the lived body. Schmitz et al. (2011:249) calls these rare situations "absolute identity": "the place of a relative identity of something with something is filled by an absolute identity of being it yourself". Regarding the experience of intercorporeality, this absolute identity might include others' lived bodies. In the case of humananimal relations such situations of collective absolute identity might be able to dissolve, or at least challenge, the very idea of "relation" and replace it with an intersubjective idea of bodily existence and a mutual concept of "being affected".

Furthermore, the concept of experienced intercorporeality might then help to overcome the idea of affect as a transient moment. Humans not only "affect" the lived body of animals; animals also affect humans. An intercorporeal crossing of the boundaries between humans and animals, as seen from the animals' perspective, could lead to demeanour changes of all actants involved. We do not have the space to further develop this research here, but we are convinced that future scholarship in this direction could forge new directions in post-humanist discussions of non-human ethics and raise, for instance, further questions of the moral self in animal conservation practice (Brown, 2014). In the case of the wild horses, however, it would be rewarding to learn more about how the nature conservation practices serve to rework their temper, how an injured horse responds to human caretaking practices, whether horses act accordingly to human expectations or whether horses feel stressed by experiencing thirst while simultaneously being observed by tourists at the waterhole viewpoint. In this regard, there is need to rethink carefully and negotiate critically the well-meant and allegedly decolonizing practice of caretaking and to shed more light on the mutual, yet hierarchical, vulnerabilities occurring in the relationship of the wildlife biologist and the horses in our case (see Parreñas, 2018).

These are continuative empirical questions beyond the scope of anthropocentric thinking. However, despite the fact that more-than-human knowledge is prolific, nature conservation scarcely appreciates this kind of intercorporeally learned knowledge. In fact, as Plumwood (1993) from the perspective of feminism already elaborated in the 
early 1990s, in many contexts it is framed as quite the opposite of a proper practice of science. The price is that anthropocentric concepts such as sustainability or biodiversity then inevitably produce anthropocentric results, a "nature for people" (Mace, 2014:1559). Currently, there is much scholarly debate on alternatives under the catchword of the "Anthropocene" accompanied by calls for epistemological and methodological changes or a new ontology of nature. However, things are not as easy as they might seem. Though we propose "learning to be intercorporeal" as a way towards post-anthropocentric or post-dualistic ontologies, we are very much aware of the limitations of such an undertaking, starting with the fact that we cannot completely divest ourselves of culturally grown presumptions and humanistic fundamentals.

What we as human scholars can do is to ask irritating questions which potentially de- and reposition world views, science and scholarly interventions. In the field of human-non-human encounters and their sustainability, Urbanik (2012:17) has argued that asking questions aimed at profiting not only humans could be a good start.

We cannot accomplish post-dualistic ontologies by means of dualistic thinking. The dualism of nature and culture is everywhere, yet in more or less institutionalized forms. It is real, even in a contingent understanding of reality (Schlottmann et al., 2010). It intersects in manifold ways with other dualisms such as human-animal or masculinefeminine (Vakoch and Mickey, 2018). It forms human identities as well as social ethics. As we showed for the NamibNaukluft National Park, it is fundamental for territorial politics and related materialization, for human practices and nonhuman agencies, for the decision of what is native or invasive, for what is worth protecting, and for rules governing life and death. However, like the national park fence, the dualism has both a limiting and an enabling side. What we can do from an epistemological stance is to follow the dualisms in more-than-human networks in order to learn more about how they operate, both in productive and harmful ways. Therefore, in keeping with, among others, Vakoch and Castrillón (2014), we need a scholarly praxis that is able to transcend the boundary between rational observation (and its technology) and phenomenological inquiry.

A phenomenological stance, in our opinion, is an important contribution towards what Lorimer (2015) has called "conservation after nature". According to our understanding, however, this should take dualisms at hand seriously. Finally, when it comes to the concept of the body as being both Körper and Leib, research for conservation as well as conservation practice should be repositioned towards learning about, and with, the lived bodies of all actors involved.

Data availability. Due to privacy laws and to protect the identities of the interviewees, the interviews are not publicly accessible.
Author contributions. The co-authors contributed equally to data generation. RP curated research data. AS wrote the original draft.

Competing interests. The authors declare that they have no conflict of interest. Antje Schlottmann is a member of the advisory board of the journal.

Acknowledgements. Many thanks to Olivier Graefe und Simone Pütz for supporting the entire project, including the research process; to Julia Poerting, Verena Schröder and Christian Steiner for helpfully commenting on earlier versions of this paper; to Heide Bruckner for her thorough editorial work; and to two anonymous referees for their most valuable comments. Last but not least, we wish to appreciate the work of the local persons involved and to thank them for letting us take part in their doing and thinking.

Review statement. This paper was edited by Myriam HoussayHolzschuch and reviewed by two anonymous referees.

\section{References}

Alaimo, S.: Bodily Natures, Indiana University Press, Bloomington, 2010.

Alaimo, S.: Exposed. Environmental Politics and Pleasures in Posthuman Times, University of Minnesota Press, Minneapolis, 2016.

Barua, M.: Lively commodities and encounter value, Environ. Plan. D, 34, 725-744, https://doi.org/10.1177/0263775815626420, 2016.

Barua, M.: Nonhuman labour, encounter value, spectacular accumulation: The geographies of a lively commodity, Trans. Inst. Brit. Geogr., 42, 274-288, https://doi.org/10.1111/tran.12170, 2017.

Bluwstein, J.: From colonial fortresses to neoliberal landscapes in Northern Tanzania: A biopolitical ecology of wildlife conservation, J. Polit. Ecol., 25, 144-168, 2018.

Brockington, D.: Fortress conservation: the preservation of the Mkomazi Game Reserve, Tanzania, The International African Institute, Oxford, Dar es Salaam, Bloomington, Indianapolis, 2002.

Brown, C.: The who of environmental ethics: Phenomenology and the moral self, in: Ecopsychology, Phenomenology, and the Environment. The Experience of Nature, edited by: Vakoch, D. A. and Castrillón, F., Springer, New York, 143-158, 2014.

Bruckner, H. K., Colombino, A., and Ermann, U.: Naturecultures and the affective (dis)entanglements of happy meat, Agr. Human Val., 45, 1-13, 2018.

Chrulew, M. and Wadiwel, D.: Editors' Introduction: Foucault and Animals, in: Foucault and Animals, Human-animal studies, vol. 18, edited by: Chrulew, M. and Wadiwel, D., Brill, Leiden, Boston, 1-15, 2017.

Cothran E. G., van Dyk, E., and van der Merwe F. J.: Genetic Variation in the feral horses of the Namib Desert, Namibia, J. S. Afr. Vet. Assoc., 72, 18-22, 2001.

De Lauretis, T.: Statement Due, Critical Inquiry, 30, 365-368, https://doi.org/10.1086/421134, 2004. 
Deleuze, G. and Guattari, F.: A Thousand Plateaus, University of Minnesota Press, Minneapolis, 1987.

Demeritt, D.: What is the 'social construction of nature'? A typology and sympathetic critique, Prog. Human Geogr., 26, 767-790, 2002.

Dutton, D.: Being-with-Animals: Modes of Embodiment in Human-Animal Encounters, in: Crossing Boundaries: Investigating Human-Animal Relationships, edited by: Birke, L. and Hockenhull, J., Brill, Leiden, Boston, 91-112, 2012.

Evans, L. and Adams, W.: Fencing Elephants, Land Use Policy, 51, 215-228, 2016.

Foucault, M.: The Order of Things: An Archaeology of the Human Sciences, Tavistock Publications Ltd., London, 1970.

Gaard, G.: Ecofeminism Revisited: Rejecting Essentialism and Re-Placing Species in a Material Feminist Environmentalism, Femin. Form., 23, 26-53, https://doi.org/10.1353/ff.2011.0017, 2011.

Gillespie, K. and Narayanan, Y.: Animal Nationalisms: Multispecies Cultural Politics, Race, and the (Un)Making of the Settler Nation-State, J. Intercult. Stud., 41, 1-7, 2020.

Goldbeck, M., Greyling, T., and Swilling, R.: Wilde Pferde in der Namibwüste, Friends of the Wild Horses, Windhoek, 2011.

Gondwana Collection: Emil Kreplin, Father of the Namib Horses, available at: https://www. gondwana-collection.com/news/article/2016/04/08/

emil-kreplin-father-of-the-namib-wild-horses/ (last access: 8 February 2019), 2016.

Grusin, R.: The Nonhuman turn, University of Minnesota Press, Minneapolis, 2015.

Haraway, D.: The companion species manifesto: Dogs, people, and significant otherness, Prickly Paradigm Press, Chicago, 2003.

Haraway, D.: When species meet, University of Minnesota Press, Minneapolis, 2008.

Hinchliffe, S., Allen, J., Lavau, S., Bingham, N., and Carter, S.: Biosecurity and the the topologies of infected life: From borderlines to borderlands, Inst. Brit. Geogr., 38, 531-543, 2013.

Husserl, E.: Ideen zu einer reinen Phänomenologie und phänomenologischen Philosophie, Husserliana, Bd. 3, Meiner, Hamburg, [1913] 2009.

Iovino, S. and Oppermann, S. (Eds.): Material Ecocriticism, Indiana University Press, Bloomington, 2014.

Jones, O.: 'The restraint of beasts': rurality, animality, Actor Network Theory and dwelling, in: Country visions, edited by: Cloke, P. J., Pearson/Prentice Hall, Harlow, England, New York, 283307, 2003.

Knudsen, B. T. and Stage C. (Eds): Affective Methodologies, Palgrave Macmillan, London, 2015.

Laclau, E.: Emanzipation und Differenz, Verlag Turia + Kant, Wien, 2002.

Latour, B.: How to talk about the body? The normative dimension of science studies, Body Soc., 10, 205-229, 2004.

Lorimer, J.: Nonhuman charisma, Environ. Plan. D, 25, 911-932, https://doi.org/10.1068/d71j, 2007.

Lorimer, J.: Wildlife in the Anthropocene: Conservation after Nature, University of Minnesota Press, Minneapolis, 2015.

Mace, G.: Whose Conservation?, Science, 345, 1558-1560, https://doi.org/10.1126/science.1254704, 2014.

Macnaghten, P. and Urry, J.: Contested Natures, SAGE, London, 1998.
Maurstad, A., Davis, D., and Cowles, S.: Co-being and intra-action in horse-human relationships: A multi-species ethnography of be(com)ing human and be(com)ing horse, Social Anthropology/Anthropologie Sociale, 21, 322-335, https://doi.org/10.1111/1469-8676.12029, 2013.

Merleau-Ponty, M.: Phenomenology of Perception, Routledge, London, [1945] 1962.

Merleau-Ponty, M.: The child's relations with others, in: The primacy of perception, edited by: Edie, J. M., Northwestern Universities Press, Evanston, IL, 96-155, 1964.

MET - Ministry of Environment and Tourism Namibia: Management Plan Namib-Naukluft Park, Windhoek, available at: http:// www.met.gov.na/files/files/NamibNaukluftManagementPlan.pdf (last access: 8 February 2019), 2013.

Meyer, C., Streeck, J., and Jordan, J. S.: Introduction, in: Intercorporeality. Emerging Socialities in Interaction, edited by: Meyer, C., Streeck, J., and Jordan, J. S., Oxford University Press, Oxford, xv-xlix, 2017.

Parreñas, J. S.: Decolonizing Extinction: The Work of Care in Orangutan Rehabilitation, Duke University Press, Durham, 2018.

Peluso, N. and Lund, C.: New frontiers of land control: Introduction, J. Peasant Stud., 38, 667-681, https://doi.org/10.1080/03066150.2011.607692, 2011.

Plessner, H. (Ed.): Lachen und Weinen, in: Philosophische Anthropologie, Fischer, Frankfurt, 11-171, [1941] 1970.

Plessner, H. (Ed.): Der Mensch als Lebewesen, in: Mit anderen Augen. Aspekte einer philosophischen Anthropologie, Reclam, Stuttgart, 9-62, 1982.

Plumwood, V.: Feminism and the Mastery of Nature, Routledge, London, New York, 1993.

Pratt, M. L.: Arts of the contact zone, Profession, 33-40, 1991.

Pütz, R.: Wildpferde in den USA. Ressourcenkonflikte, Wildniskonstruktionen und Mensch-Wildtier-Verhältnisse, Geogr. Rundschau, 69, 46-51, 2017.

Pütz, R.: Pferderücken, in: Räume der Kindheit. Ein Glossar, edited by: Hasse, J. and Schreiber, V., transcript, Bielefeld, 259-265, 2019.

Pütz, R.: Making Companions: Companionability and Encounter Value in the Marketization of the American Mustang, Environ. Plan. E, https://doi.org/10.1177/2514848620924931, in press, 2020.

Rutherford, S.: Governing the Wild. Ecotours of Power, University of Minnesota Press, Minneapolis, 2011.

Schlottmann, A., Graefe, O., and Korf, B.: Emotions outside the box. The new phenomenology of feeling and corporality, Phenomenol. Cognit. Sci., 10, 241-259, 2010.

Schmitz, H., Müllan, R. O., and Slaby, J.: Emotions outside the box - the new phenomenology of feeling and corporeality, Phenomenol. Cognit. Sci., 10, 241-259, 2011.

Schwartz, S.: Nachhaltigkeit als Komplexitätsfalle, Monsenstein und Vannerdat OHG Münster, Münster, 2015.

Searle, J. R.: The construction of social reality, Penguin, London, 1995.

Steiner, C.: Pragmatismus, Umwelt, Raum: Potenziale des Pragmatismus für eine transdisziplinäre Geographie der Mitwelt, in: Erdkundliches Wissen, Band 155, Franz Steiner Verlag, Stuttgart, 2014. 
Swilling, R.: Running the wild horses of the Namib, available at: https://www.countrylife.co.za/travel/heritage/ wild-horses-namibia, last access: 10 May 2020.

Tanaka, S.: Intercorporeality and aida: Developing an interaction theory of social cognition, Theor. Psychol., 27, 337-353, https://doi.org/10.1177/0959354317702543, 2017.

Thrift, N.: Still life in nearly present time: the object of nature, in: Country visions, edited by: Cloke, P. J., Pearson/Prentice Hall, Harlow, England, New York, 308-332, 2003.

Tremmel, J.: Nachhaltigkeit als politische und analytische Kategorie, oekom verlag, München, 2003.

Urbanik, J.: Placing Animals: An Introduction to the Geography of Human-Animal Relations, Rowman \& Littlefield, Plymouth, 2012.

Vakoch, D. A. and Castrillón, F. (Eds.): Ecopsychology, Phenomenology, and the Environment, in: The Experience of Nature, Springer, New York, 2014.
Vakoch, D. A. and Mickey, S. (Eds.): Women and Nature?, Beyond Dualism in Gender, Body, and Environment, Routledge, New York, 2018.

Westling, L.: The Logos of the Living World. Merleau-Ponty, Animals, and Language, Fordham University Press, New York, 2013.

Whatmore, S.: Hybrid geographies: Natures, cultures, spaces, XIII, Sage, London, 2002.

Whatmore, S. and Thorne, L.: Wild(er)ness: Reconfiguring the Geographies of Wildlife, Trans. Inst. Brit. Geogr., 23, 435-454, https://doi.org/10.1111/j.0020-2754.1998.00435.x, 1998.

Whatmore, S. and Thorne, L.: Elephants on the Move: Spatial Formations of Wildlife Exchange, Environ. Plan. D, 18, 185-203, https://doi.org/10.1068/d210t, 2000.

Wolch, J.: Anima urbis, Prog. Human Geogr., 26, 721-742, https://doi.org/10.1191/0309132502ph400oa, 2002. 